\title{
Medical cannabis: What practitioners need to know
}

\author{
R van Rensburg, ${ }^{1}$ MB ChB, Dip HIV Man (SA); V Pillay-Fuentes Lorente, ${ }^{1}$ MB ChB, PG Dip (Med Dev); \\ M Blockman, ${ }^{2}$ BPharm, MB ChB, PG Dip Int Res Ethics, MMed (Clin Pharm); \\ K Moodley, ${ }^{3}$ MB ChB, MFamMed, FCFP (SA), MPhil (Applied Ethics), Executive MBA, DPhil; \\ J M Wilmshurst, ${ }^{4}$ MBBS, MRCPaed (UK), FCPaed (SA), MD; E H Decloedt, ${ }^{1}$ MB ChB, BSc Hons, FCCP (SA), MMed (Clin Pharm), PhD
}

\author{
${ }^{1}$ Division of Clinical Pharmacology, Department of Medicine, Faculty of Medicine and Health Sciences, Stellenbosch University, Cape Town, \\ South Africa \\ ${ }^{2}$ Division of Clinical Pharmacology, Department of Medicine, Faculty of Health Sciences, University of Cape Town, South Africa \\ ${ }^{3}$ Centre for Medical Ethics and Law, Department of Medicine, Faculty of Medicine and Health Sciences, Stellenbosch University, Cape Town, South Africa \\ ${ }^{4}$ Division of Paediatric Neurology, Department of Paediatrics and Child Health, Red Cross War Memorial Children's Hospital and \\ Neurosciences Institute, University of Cape Town, South Africa
}

Corresponding author: E H Decloedt (ericdecloedt@sun.ac.za)

\begin{abstract}
The South African (SA) Constitutional Court recently decriminalised the private cultivation, possession and use of cannabis by adults. Cannabis contains varying amounts of the cannabinoids delta-9-tetrahydrocannabinol (THC) and cannabidiol (CBD), depending on various cultivation factors. No commercial plant-derived cannabis products are currently registered by the SA Health Products Regulatory Authority (SAHPRA) for medical use. Such products are therefore unregulated, but are freely available in SA, and may be of inadequate quality and unverified composition, and not guaranteed to be safe or effective. SAHPRA has to date approved only one synthetic medical cannabis product, dronabinol. Evidence supporting benefit from medical cannabis exists for two drug-resistant childhood forms of epilepsy, Dravet syndrome and Lennox-Gastaut syndrome. Adjuvant therapy with medical cannabis can reduce seizure frequency for LennoxGastaut syndrome and Dravet syndrome by $18.8 \%$ and $22.8 \%$, respectively, and may be beneficial for other rare forms of epilepsy. There is moderate evidence for chemotherapy-induced nausea and vomiting with the synthetic cannabinoids. Multiple sclerosis-associated spasticity showed a small clinical improvement in self-reported spasticity when a purified form of THC/CBD was added to existing therapy. Currently, low-level or no convincing evidence exists for the use of medical cannabis for chronic pain, sleep and weight disorders, and neuropsychiatric disorders. Cannabis is associated with a greater risk of adverse effects than active and placebo controls, and may be involved in clinically significant drug-drug interactions. The evolving regulatory and legal landscape on the use of medical cannabis will guide prescription and recreational use in the coming years.
\end{abstract}

S Afr Med J 2020;110(3):192-196. https://doi.org/10.7196/SAMJ.2020.v110i3.14403

On 18 September 2018, the South African (SA) Constitutional Court decriminalised the cultivation, possession and use of cannabis in private by adults. ${ }^{[1]}$ Section $22 \mathrm{~A}(9)(\mathrm{a})(\mathrm{i})$ of the Medicines and Related Substances Act (Act 101 of 1965) was deemed to be constitutionally invalid and the wording needed to be revised by Parliament. In February 2019, the SA Health Products Regulatory Authority (SAHPRA) issued a communication that the Constitutional Court judgment should not be interpreted that persons are allowed to prepare cannabis-containing products in a private place and sell such products to the public. ${ }^{[2]}$ Provisions of section 14(1) of the Medicines and Related Substances Act prohibit the selling of unregistered cannabis-containing medicines and products that are currently available in SA. In May 2019, this Act was subsequently amended by the Minister of Health to exclude from the schedule of medicines cannabidiol (CBD)-containing preparations with a maximum daily dose $\leq 20 \mathrm{mg}$ CBD, or raw cannabis materials that do not contain $>0.0075 \% \mathrm{CBD}$ and $0.001 \%$ delta-9-tetrahydrocannabinol (THC) ${ }^{[3]}$ Such preparations should, however, have acceptable low risk and health claims. For patients and healthcare practitioners, this is in conflict with several outlets and individuals selling cannabiscontaining products (including oils) for medical use, with much higher concentrations of CBD and other cannabinoids, and with sensational health claims. Few healthcare practitioners are equipped with knowledge of the evidence, indications and legislation to support the safe use of medical cannabis. ${ }^{[4]}$ In this overview, we summarise the indications for the clinical administration of medical cannabis, how practitioners may access medical cannabis and the current published evidence base. We emphasise that unregulated and unregistered cannabis products sold as medical cannabis may be of inadequate quality and unverified composition, and are not guaranteed to be safe or effective.

\section{Cannabinoids and medical cannabis}

The pharmacologically active ligands in medical cannabis are the cannabinoids. Over the past years, almost 200 cannabinoids have been identified, and the type of cannabinoids differs depending on whether they are endogenous (endocannabinoids), plant derived (phytocannabinoids) or synthetic. ${ }^{[5-7]}$ The endocannabinoid system consists of endogenous lipid-based neurotransmitters that bind to cannabinoid receptors expressed widely throughout the body. The endocannabinoid system purportedly has two types of receptors, $\mathrm{CB}_{1}$ and $\mathrm{CB}_{2}{ }^{\left[{ }^{[8]}\right.} \mathrm{CB}_{1}$ receptors are abundant in the brain and central nervous system, but are also found in various other tissues. ${ }^{[9]} \mathrm{CB}_{1}$ receptors are thought to regulate functions such as memory, nausea and vomiting, nociception, sleep and appetite. ${ }^{[8,9]} \mathrm{CB}_{2}$ receptors are mostly found in immune cells and the cardiovascular, gastrointestinal 
and reproductive systems, where it is considered to regulate various functions. ${ }^{[9,10]}$ The $\mathrm{CB}_{1}$ and $\mathrm{CB}_{2}$ receptors can be stimulated by endocannabinoids, phytocannabinoids or synthetic cannabinoids. ${ }^{[6]}$ An important consideration is that the affinity and potency of the different cannabinoids for $\mathrm{CB}_{1}$ and $\mathrm{CB}_{2}$ receptors differ such that efficacy and safety of one cannabinoid cannot be applied to another. ${ }^{[11,12]}$

Phytocannabinoids are isolated from the Cannabis sativa and Cannabis indica plants. THC and CBD are the most widely researched phytocannabinoids. ${ }^{[13,14]}$ The psychoactive effects of cannabis have been attributed to THC, a major compound of the C. sativa plant, while CBD is thought to inhibit these effects. ${ }^{[15]} \mathrm{THC}$ functions as an agonist with high affinity for both $\mathrm{CB}_{1}$ and $\mathrm{CB}_{2}$ receptors. $\mathrm{CBD}$ has low affinity for $\mathrm{CB}_{1}$ and $\mathrm{CB}_{2}$, and displays antagonism and inverse agonism at these receptors. ${ }^{[16]}$ This implies that the ratio of THC and $\mathrm{CBD}$ in phytocannabinoids would affect the ultimate clinical effect. The strain of cannabis and the cultivation environment, such as soil type, irrigation, harvesting and processing, all affect the quality and composition of phytocannabinoids. ${ }^{[17,18]}$ Different parts of the cannabis plant also have differing concentrations of phytocannabinoids, with THC generally being most abundant in the flowers and leaves, and CBD in the leaves and stems. ${ }^{[17]}$

Cannabis products are therefore prone to variability, which underpins the strict enforcement of the Medicines and Related Substances Act by SAHPRA. Accordingly, unregulated and unregistered cannabis products sold as medical cannabis may be of inadequate quality and unverified composition, and are not guaranteed to be safe or effective.

Medical cannabis refers to medical products that contain purified phytocannabinoids or synthetically derived cannabinoids that have been approved by regulatory authorities for medical use ${ }^{[18]}$ Regulatory authorities evaluate medical cannabis products for acceptable product variability, and only effective, safe and good-quality products complying with good manufacturing practices (GMP) are marketed. ${ }^{[1,20]}$ To date, the US Food and Drug Administration (FDA) has approved three drugs that contain cannabinoids: a plant-derived CBD solution, and two synthetic cannabinoids structurally related to THC, nabilone and dronabinol. ${ }^{[18,20]}$ A purified form of THC and CBD in a 1:1 ratio, known as nabiximols, has been approved by Health Canada and several other countries. ${ }^{[19,21]}$ Approved medical cannabis products on the market are oral formulations administered either as capsules, oral solutions or oromucosal sprays. ${ }^{[22-26]}$ These standardised preparations aim to provide accurate dosing and improve safety. ${ }^{[18]}$

Numerous products that contain raw or herbal cannabis, also referred to as non-medical products, have not received approval from the FDA or other regulatory authorities, such as the European Medicines Agency (EMA). ${ }^{[27]}$ Many of these unregulated products that are readily available on the market claim to contain only CBD, but some contain both CBD and THC that differ in their CBD:THC ratios. ${ }^{[19]}$ They also tend to contain higher amounts of psychoactive THC and lower amounts of CBD than regulated products. ${ }^{[19]}$ A study evaluating the accuracy of labelling of unregulated cannabis-containing products in various states in the USA, showed discrepancies between the labelling and actual CBD and THC content. ${ }^{[28,29]}$ Unregulated cannabis products are freely available on the open market and unknowing patients and carers can access these formulations, which are sold with unfounded claims regarding efficacy and safety. ${ }^{[30]}$ There are $>480$ constituents in cannabis plants, ${ }^{[31]}$ which can lead to significant variation in unregulated cannabis products. Therefore, the quality, efficacy and safety of these unregulated products are questionable. Importantly, regulatory oversight is essential for ongoing safety monitoring of medicines. In 2008, the anti-obesity drug rimonabant, a synthetic $\mathrm{CB}_{1}$ antagonist and inverse agonist, ${ }^{[32]}$ was withdrawn from the European market after approval in 2006, owing to serious central nervous system side-effects. ${ }^{[33]}$ SAHPRA has to date approved only one medical cannabis product, dronabinol, for marketing in SA, ${ }^{[2]}$ although section 21 approval has been granted for some cannabis-containing products registered in other countries to meet local clinical needs. ${ }^{[2]}$ Section 21 of the Medicines Act allows controlled patient access to medical cannabis registered by other regulatory authorities to which SAHPRA aligns. For patients to access these medicines that are not registered in SA, a medical practitioner needs to apply to SAHPRA to allow specific named patient access.

\section{Evidence for the use of medical cannabis}

Clinical evidence of the indications for the use of medical cannabis is currently supported by a limited evidence base, but the field is evolving. Medical cannabis has been shown to be effective for certain conditions, but the benefit for most investigated indications is limited, in many cases by poor-quality studies, risk of bias and clinically nonsignificant findings. ${ }^{[34]}$ The synthetic cannabinoids were mostly assessed, as standardisation of phytocannabinoids cannot be ensured, and the bioavailability of inhaled cannabis cannot be guaranteed. Evidence supporting benefit from the use of medical cannabis exists for two drug-resistant childhood forms of epilepsy, Dravet syndrome and Lennox-Gastaut syndrome. ${ }^{[35]}$ Three randomised controlled trials (RCTs) assessed the effect of a pharmaceutical plant-derived CBD solution (Epidiolex), and found that when added as adjuvant therapy at the maximum recommended dose, it led to a significant reduction in the median frequency of monthly seizures when compared with placebo for Lennox-Gastaut syndrome $(-18.8 \%$; $95 \%$ confidence interval (CI) $-31.8-4.4 ; p=0.009),{ }^{[36,37]}$ and for Dravet syndrome $(-22.8 \%$; $95 \%$ CI $-41.1--5.4 ; p=0.01) .{ }^{[38]}$ Based on these findings, the FDA approved the plant-derived CBD for Dravet and LennoxGastaut syndromes, ${ }^{[39]}$ and approval by the EMA followed thereafter. Long-term therapy with CBD in these epilepsy syndromes has also found sustained response and acceptable tolerability. ${ }^{[40,41]}$ Data for other types of epilepsy are more limited, but there does appear to be benefit for children and adults who have epilepsy that is refractory to appropriately dosed antiseizure medications. ${ }^{[42]}$ An open-label drug trial established modest evidence for the long-term safety and efficacy of CBD administration in patients with medically refractory epilepsy associated with cyclin-dependent kinase-like 5 (CDKL5) mutations, as well as Aicardi syndrome, 15q11-q13 duplication (dup15q), also known as the Prader-Willi/Angelman critical region (PWACR), and myoclonic-atonic (Doose) syndromes. ${ }^{[43]}$ However, even with this apparent tolerability, clinicians must be aware of potential drug-drug interactions between the commonly used antiseizure medications and CBD. As an example, clobazam plasma concentrations are increased when administered with $\mathrm{CBD} ;{ }^{[44]}$ this potentiation of activity has been noted as an independent factor in the apparent improved response of epilepsy to CBD. ${ }^{[45]}$ Studies in patients not using clobazam and other interacting medications will be important in the future. ${ }^{[45]}$

For other conditions, there is moderate evidence for the management of chemotherapy-induced nausea and vomiting (CINV) and multiple sclerosis (MS)-associated spasticity. The synthetic cannabinoids dronabinol and nabilone showed the best efficacy in reducing CINV, but the risk of bias and lack of consistency of findings in trials limit their recommendation. ${ }^{[34,46]}$ Nevertheless, dronabinol 
and nabilone have both received FDA approval for refractory CINV. ${ }^{[23,24]}$ Nabiximols showed a small, but significant, clinical improvement in self-reported MS-associated spasticity when added to existing therapy. ${ }^{[34,47]}$ Evidence for an overall beneficial effect of dronabinol for MS-associated spasticity, however, was not found. ${ }^{[48]}$

Currently, low-level or no convincing evidence exists for chronic pain, sleep and weight, or neuropsychiatric disorders. Chronic pain studies evaluated a wide spectrum of differing pain conditions, outcome measures and cannabinoids, with most studies having a high or unclear risk of bias. ${ }^{[34,49,50]}$ Some studies showed significant findings, but were not consistent across trials. ${ }^{[34,49]}$ Furthermore, improvement in pain scores were generally not clinically significant (e.g. a weighted mean difference in pain improvement of 0.46 points on an 11-point numeric rating scale $(0-10)) .{ }^{[34]} \mathrm{A}$ trend towards benefit for neuropathic pain, however, was suggested. ${ }^{[50]}$

A meta-analysis ${ }^{[49]}$ pooling 9 RCTs estimated that the number needed to treat to benefit for at least a $30 \%$ reduction in pain for any chronic pain condition was $24(95 \%$ CI 15 - 61). This implies that 24 patients need to be treated for 1 patient to have a $30 \%$ reduction in pain. The number needed to harm for any adverse effect was 6 (95\% CI 5 - 8).

Studies assessing cannabis for sleep, weight gain and neuropsychiatric disorders (depression, anxiety and psychosis) did not show meaningful benefit. These trials had significant limitations of low quality, high risk of bias, small sample sizes and/or nonsignificant clinical implications. ${ }^{[34]}$

\section{Harm-benefit ratio}

Before prescribing any medicine, the harm-benefit ratio should be evaluated. Cannabis is associated with a greater risk of adverse effects (AEs) than active and placebo controls, including serious AEs and withdrawal from studies due to AEs. ${ }^{[34,49,50]}$ The risk of AEs are independent of the type of cannabinoid used. Common AEs included gastrointestinal disorders, dizziness, cognitive and neuropsychiatric disorders and nausea. ${ }^{[34,49,50]}$ Medical cannabinoids (phyto and synthetic) have the potential to alter concomitantly administered drug plasma concentrations via drug-drug interactions. ${ }^{[51]}$ Conversely, cannabinoid concentrations may in turn be altered by the effect of other drugs. This is primarily mediated through inhibition or induction of the cytochrome P450 (CYP450) enzymes, but may also involve inhibition or induction of conjugation reactions. ${ }^{[51]}$ While these interactions pose a potential risk, there is a paucity of data to guide clinical decision-making.

A likely hindrance for access to registered medical cannabis is cost. As an example, the CBD solution marketed as Epidiolex (accessible via the section 21 process), when added as adjuvant therapy to existing antiseizure medication, currently costs ZAR28 528 for a $100 \mathrm{~mL}$ solution. This translates to $2-4$ weeks of treatment for an average-weight child receiving standard doses of Epidiolex. At the time of publication, we could not source pricing for dronabinol (Marinol or Syndros), nabilone (Cesamet), or nabiximols (Sativex).

\section{Ethical aspects}

Ethical concerns related to the medical use of cannabis remain complex. The medical profession has the challenging role of respecting the autonomy of the patient while balancing the principles of beneficence, non-maleficence and justice. ${ }^{[52]}$ This requires evidence of efficacy and safety of the various products available, which in itself is a contested space. Indiscriminate prescribing of a product with THC has the potential to affect cognition, which may impair rational decision-making. ${ }^{[53]}$ Harm to the individual patient and harm to society then become important considerations. There is therefore an ethical duty on the medical practitioner to ensure responsible prescribing of THC-containing medical cannabis products, and provision of advice to patients. The addition of $\mathrm{CBD}$ to products containing THC has been shown to reduce the risk of impaired cognition. ${ }^{[5,55]}$ Some unregulated cannabis products have been assessed and found to vary in their THC and CBD content when compared to information on the label, and some commercially available products sold as pure CBD contain marked amounts of THC. ${ }^{[29,30]}$ This may affect cognition, and where children and adolescents are concerned, this is particularly important, given the potential for the impact on brain development, cognitive function and mental illness. ${ }^{\left[{ }^{66]}\right]}$ Where good evidence of efficacy exists in the context of failed conventional therapy, beneficence will support the prescription of a registered safe product.

\section{Legall aspects}

In the 1860s, when Indians were brought to work as indentured labourers on the sugarcane plantations in Natal, cannabis use was introduced in that part of the country. This became a source of great concern for their colonial masters, who feared it would impact negatively on productivity and work ethic. Consequently, by 1870 , legislation was introduced in the form of Natal's Coolie Law Consolidation, prohibiting the cultivation, possession and use of cannabis. ${ }^{[57]}$ By 1922, more stringent laws were in place to prevent use. The burden of proof rested with the accused, unlike other legislation at the time for alcohol, where the burden of proof rested with the accuser. ${ }^{[58]}$ In many respects, a judgement call was made on the use of cannabis as a social ill that would corrupt the indentured labourers and others in society. ${ }^{[5,60]}$ Hence, the laws were particularly punitive, exceeding the legislation on alcohol and smoking that were regarded as 'civilised' Western substances to use and abuse. ${ }^{[58]}$ Given that cannabis was widely used by indigenous people in SA, the legislation around cannabis was in keeping with apartheid legislation and hence restricted rights to privacy. ${ }^{[59]}$ In the judgment on the decriminalisation of cannabis, the High Court stated that much of the history of cannabis use in SA 'is replete with racism. ${ }^{[1]}$

The criminalisation of the private use, possession and cultivation of cannabis by adults was ruled unconstitutional in terms of section 14 of the SA Constitution that protects the right to privacy. The Constitutional Court also ruled that sections of the Drugs and Drug Trafficking Act 104 of 1992 and the Medicines and Related Substances Act violated this right to privacy in a way that could not be justified in terms of the limitation clause of the Bill of Rights. ${ }^{[1]}$ The SA Central Drug Authority argued that alcohol and smoking cause more individual and societal harm than cannabis, ${ }^{[61,62]}$ and subsequently the personal use of cannabis by adults in private was decriminalised in 2018. ${ }^{[1]}$

Over the next 2 years, it is anticipated that decriminalisation will progress to legalisation and regulation. This will require comprehensive guidance on the quality of cannabis production, the quantity that is legally permissible for private growth, possession and use by adults, how minors and adolescents will be protected, and how promotion and enticement will be restricted. Sanctions for violating legislation will also need to be determined. These legal developments should be accompanied by intense community-engagement strategies that raise awareness of the harms and benefits of cannabis use. The promotion of public awareness, the development of educational material and the provision of rehabilitation services should occur in parallel with legal reform. 


\section{Conclusions}

High-quality evidence for medical cannabis is still in its infancy. Regulatory overview of the use of medical cannabis is essential to ensure the availability of safe, effective and good-quality products. Overall, the current limited benefits of medical cannabis for most indications may be outweighed by the lack of consistent efficacy and risk of adverse effects, including multiple drug interactions with no data to guide management. Currently, for the majority of proposed medical cannabis indications, safer and generally more effective pharmacological therapies are regulatorily approved. However, goodquality data support the use of medical cannabis for rare forms of childhood epilepsy resistant to current registered antiseizure medications. This may justify facilitated access in SA to medical cannabis via section 21. Medical cannabis could also be considered for patients with intractable CINV and MS-associated spasticity. Unfortunately, the cost of medical cannabis may be prohibitive for these patient groups. The regulatory and legal landscape on the use of medical cannabis is evolving, and will guide prescription and recreational use in the coming years. Until such time, healthcare practitioners should be aware of their role in responsible prescription and provision of advice to patients.

\section{Key points}

- Few healthcare practitioners are adequately equipped with knowledge of the evidence, indications and legislation to support the safe use of medical cannabis.

- Grown cannabis contains varying amounts of THC and CBD, depending on various cultivation factors.

- Unregulated and unregistered cannabis products may be of inadequate quality and unverified composition, and are not guaranteed to be safe or effective.

- Convincing evidence exists for the use of registered medical cannabis for Dravet and Lennox-Gastaut syndromes. Moderate evidence exists for the management of CINV and MS-associated spasticity. Currently, low-level or no convincing evidence exists for chronic pain, sleep and weight disorders, and neuropsychiatric disorders.

- Cannabis is associated with a greater risk of adverse effects than active and placebo controls, including serious adverse effects.

- The evolving regulatory and legal landscape on the use of medical cannabis will guide prescription and recreational use in the coming years.

\section{Declaration. None.}

Acknowledgements. None.

Author contributions. All authors contributed equally.

Funding. None.

Conflicts of interest. None.

1. Minister of Justice and Constitutional Development and Others v Prince (Clarke, Stobbs and Thorpe Intervening) (Doctors of Life International Inc as Amicus Curiae); National Director of Public Prosecutions and Others v Rubin; National Director of Public Prosecutions and Others v Acton and Others 2017

2. South African Health Products Regulatory Authority. Status of cannabis-containing products (including oils) and the cultivation of cannabis for medicinal use. 2019. https://www.sahpra.org.za/ Publications/DownloadDoc/5576 (accessed 1 July 2019).

3. National Department of Health, South Africa. Medicines and Related Substances Act, 1965 (Act No. 101 of 1965). Exclusion of certain preparations containing cannabidiol (CBD) from operation of certain provisions of the Act. Government Gazette No. 10949:42477. 2019.

Gardiner KM, Singleton IA, Sheridan I, Kyle GJ, Nissen LM. Health professional beliefs, knowledge and concerns surrounding medicinal cannabis - a systematic review. PLoS ONE 2019;14(5):e0216556. and concerns surrounding medicinal cannabis

5. Hanuš LO, Meyer SM, Muñoz E, Taglialatela-Scafati O, Appendino G. Phytocannabinoids: A unified critical inventory. Nat Prod Rep 2016;33(12):1357-1392. https://doi.org/10.1039/c6np00074f

6. Chakravarti B, Ravi J, Ganju RK. Cannabinoids as therapeutic agents in cancer: Current status an future implications. Oncotarget 2014;5(15):5852-5872. https://doi.org/10.18632/oncotarget.2233

7. Fisar Z. Phytocannabinoids and endocannabinoids. Curr Drug Abus Rev 2009;2(1):51-75. https://doi. org/10.2174/187447371090201005
8. Kaur R, Ambwani S, Singh S. Endocannabinoid system: A multi-facet therapeutic target. Curr Clin Pharmacol 2016;11(2):110-117. https://doi.org/10.2174/1574884711666160418105339

9. Zou S, Kumar U. Cannabinoid receptors and the endocannabinoid system: Signaling and function in the central nervous system. Int J Mol Sci 2018;19(3):833. https://doi.org/10.3390/ijms19030833

10. Sviženská I, Dubový P, Šulcová A. Cannabinoid receptors 1 and 2 (CB1 and CB2), their distribution, ligands and functional involvement in nervous system structures - a short review. Pharmacol Biochem Behav 2008;90(4):501-511. https://doi.org/10.1016/j.pbb.2008.05.010

11. Nahtigal I, Blake A, Hand A, Florentinus-Mefailoski A, Hashemi H, Friedberg J. The pharmacological properties of cannabis. J Pain Manage 2016;9(4):481-491.

12. Borgelt LM, Franson KL, Nussbaum AM, Wang GS. The pharmacologic and clinical effects of medical cannabis. Pharmacotherapy 2013;33(2):195-209. https://doi.org/10.1002/phar.1187

13. Russo EB. Taming THC: Potential cannabis synergy and phytocannabinoid-terpenoid entourage effects. Br J Pharmacol 2011;163(7):1344-1364. https://doi.org/10.1111/j.1476-5381.2011.01238.x

14. Bow EW, Rimoldi JM. The structure-function relationships of classical cannabinoids: $\mathrm{CB} 1 / \mathrm{CB} 2$ Bow EW, Rimoldi JM. The structure-function relationships of classical cannabinoins:
modulation. Perspect Medicin Chem 2016;8:17-39. https://doi.org/10.4137/pmc.s32171

15. Swift W, Wong A, Li KM, Arnold JC, McGregor IS. Analysis of cannabis seizures in NSW, Australia: Cannabis potency and cannabinoid profile. PLoS ONE 2013;8(7):e70052. https://doi.org/10.1371/ journal.pone. 0070052

16. Pertwee RG, Howlett AC, Abood ME, et al. International Union of Basic and Clinical Pharmacology. LXXIX. Cannabinoid receptors and their ligands: Beyond CB1 and CB2. Pharmacol Rev 2010;62(4):588-631. https://doi.org/10.1124/pr.110.003004

17. Andre CM, Hausman J-F, Guerriero G. Cannabis sativa: The plant of the thousand and one molecules. Front Plant Sci 2016;7:19. https://doi.org/10.3389/fpls.2016.00019

18. European Monitoring Centre for Drugs and Drug Addiction. Medical Use of Cannabis and Cannabinoids: Questions and Answers for Policymaking. Luxembourg: Publications Office of the European Union, 2018. http://www.emcdda.europa.eu/system/files/publications/10171/20185584 TD0618186ENN_PDF.pdf (accessed 1 July 2019).

19. Freeman TP. Hindocha C, Green SF, Bloomfield MAP. Medicinal use of cannabis based products and cannabinoids. BMJ 2019;365:11141. https://doi.org/10.1136/bmj.11141

20. US Food and Drug Administration. FDA Regulation of Cannabis and Cannabis-Derived Products: Questions and Answers. Maryland: FDA, 2019. https://www.fda.gov/about-fda/about-website/ website-policies (accessed 4 July 2019).

21. Sativex. Package insert. GW Pharma. 2015. https://www.bayer.ca/omr/online/sativex-pm-en.pdf (accessed 4 July 2019)

22. US Food and Drug Administration. FDA approves first drug comprised of an active ingredient derived from marijuana to treat rare, severe forms of epilepsy. 2018. https://www.fda.gov/news-events/pressannouncements/fda-approves-first-drug-comprised-active-ingredient-derived-marijuana-treat-raresevere-forms (accessed 5 July 2019).

23. Marinol. Package insert. AbbVie. 2017. https://www.accessdata.fda.gov/drugsatfda_docs/label/2017/018651s029lbl.pdf (accessed 5 July 2019).

24. Cesamet. Package insert. Valeant. 2006, https://wwwaccessdata fda gov/drugsatfda_docs/ label/2006/018677s011lbl.pdf (accessed 5 July 2019).

25. Electronic Medicines Compendium (EMC). Sativex Oromucosal Spray - summary of product characteristics. Cambridge: GW Pharma, 2018. https://www.medicines.org.uk/emc/product/602/ smpc (accessed 2 July 2019).

26. Epidiolex. Package insert. Greenwich Biosciences. 2018. https://www.accessdata.fda.gov/drugsatfda docs/label/2018/2103651bl.pdf (accessed 5 July 2019).

27. Abuhasira R, Shbiro L, Landschaft Y. Medical use of cannabis and cannabinoids containing products - regulations in Europe and North America. Eur J Intern Med 2018;49:2-6. https://doi.org/10.1016/j. ejim.2018.01.001

28. Vandrey R, Raber JC, Raber ME, Douglass B, Miller C, Bonn-Miller MO. Cannabinoid dose and label accuracy in edible medical cannabis products. JAMA 2015;313(24):2491-2493. https://doi. org/10.1001/jama.2015.6613

29. Bonn-Miller MO, Loflin MJE, Thomas BF, Marcu JP, Hyke T, Vandrey R. Labeling accuracy of cannabidiol extracts sold online. JAMA 2017;318(17):1708-1709. https://doi.org/10.1001/ jama.2017.11909

30. US Food and Drug Administration. FDA warns companies marketing unproven products, derived from marijuana, that claim to treat or cure cancer. 2017. https://www.accessdata.fda.gov/drugsatfda_ docs/label/2018/210365lbl.pdf (accessed 5 July 2019).

31. Cabral GA. Marijuana and cannabinoids. J Cannabis Therapeutics 2001;1(3-4):61-85. https://doi, org $/ 10.1300 / j 175 \mathrm{v} 01 \mathrm{ln} 03 \_06$

32. Xie S, Furjanic MA, Ferrara JJ, et al. The endocannabinoid system and rimonabant: A new drug with a novel mechanism of action involving cannabinoid CB1 receptor antagonism - or inverse agonism - as potential obesity treatment and other therapeutic use. J Clin Pharm Ther 2007;32(3):209-231. https:// potential obesity treatment and other ther.
doi.org/10.1111/j.1365-2710.2007.00817.x

33. Sam AH, Salem V, Ghatei MA. Rimonabant: From RIO to ban. J Obes 2011;2011:1-4. https://doi. org $/ 10.1155 / 2011 / 432607$

34. Whiting PF, Wolff RF, Deshpande S, et al. Cannabinoids for medical use: A systematic review and meta-analysis. JAMA 2015;313(24):2456-2473. https://doi.org/10.1001/jama.2015.6358

35. Chen JW, Borgelt LM, Blackmer AB. Cannabidiol: A new hope for patients with Dravet or Lennox-Gastaut syndromes. Ann Pharmacother 2019;53(6):603-611. https://doi. org/10.1177/1060028018822124

36. Devinsky O, Patel AD, Cross JH, et al. Effect of cannabidiol on drop seizures in the Lennox-Gastaut syndrome. N Engl J Med 2018;378(20):1888-1897. https://doi.org/10.1056/nejmoa171463

37. Thiele EA, Marsh ED, French JA, et al. Cannabidiol in patients with seizures associated with LennoxGastaut syndrome (GWPCARE4): A randomised, double-blind, placebo-controlled phase 3 trial. Lancet 2018;391(10125):1085-1096. https://doi.org/10.1016/s0140-6736(18)30136-3

38. Devinsky O, Cross JH, Laux L, et al. Trial of cannabidiol for drug-resistant seizures in the Dravet syndrome. N Engl J Med 2017;376(21):2011-2020. https://doi.org/10.1056/nejmoal611618

39. Drugs.com. FDA approves Epidiolex. 2018. https://www.drugs.com/newdrugs/fda-approvesepidiolex-cannabidiol-lennox-gastaut-syndrome-dravet-syndrome-4769.html (accessed 5 July 2019).

40. Thiele E, Marsh E, Mazurkiewicz-Beldzinska M, et al. Cannabidiol in patients with Lennox-Gastaut syndrome: Interim analysis of an open-label extension study. Epilepsia 2019;60(3):419-428. https:// doi.org/10.1111/epi.14670

41. Devinsky O, Nabbout R, Miller I, et al. Long-term cannabidiol treatment in patients with Dravet syndrome: An open-label extension trial. Epilepsia 2019;60(2):294-302. https://doi.org/10.1111/ epi.14628

42. Szaflarski JP, Bebin EM, Comi AM, et al. Long-term safety and treatment effects of cannabidiol in children and adults with treatment-resistant epilepsies: Expanded access program results. Epilepsia 2018:59(8):1540-1548. https://doi.org/10.1111/epi.14477

43. Devinsky O, Verducci C, Thiele EA, et al. Open-label use of highly purified CBD (Epidiolex $x^{8}$ ) in patients with CDKL5 deficiency disorder and Aicardi, Dup15q, and Doose syndromes. Epilepsy Behav 2018;86:131-137. https://doi.org/10.1016/j.yebeh.2018.05.013

44. Geffrey AL, Pollack SF, Bruno PL, Thiele EA. Drug-drug interaction between clobazam and cannabidiol in children with refractory epilepsy. Epilepsia 2015;56(8):1246-1251. https://doi.org/10.1111/epi.13060 
45. Devinsky O, Marsh E, Friedman D, et al. Cannabidiol in patients with treatment-resistant epilepsy: An open-label interventional trial. Lancet Neurol 2016;15(3):270-278. https://doi.org/10.1016/s14744422(15)00379-8

46. Tafelski S, Häuser W, Schäfer M. Efficacy, tolerability, and safety of cannabinoids for chemotherapyinduced nausea and vomiting - a systematic review of systematic reviews. Schmerz 2016;30(1):14-24. https://doi.org/10.1007/s00482-015-0092-

47. Novotna A, Mares J, Ratcliffe S, et al. A randomized, double-blind, placebo-controlled, parallelgroup, enriched-design study of nabiximols* ${ }^{*}\left(\right.$ Sative $\left.^{*}\right)$, as add-on therapy, in subjects with refractory spasticity caused by multiple sclerosis. Eur J Neurol 2011;18(9):1122-1131. https://doi.org/10.1111/ j.1468-1331.2010.03328.x

48. Otero-Romero S, Sastre-Garriga J, Comi G, et al. Pharmacological management of spasticity in multiple sclerosis: Systematic review and consensus paper. Mult Scler J 2016;22(11):1386-1396. https:// doi.org/10.1177/1352458516643600

49. Stockings E, Campbell G, Hall WD, et al. Cannabis and cannabinoids for the treatment of people with chronic noncancer pain conditions. Pain 2018;159(10):1932-1954. https://doi.org $/ 10.1097 / \mathrm{j}$.
. with chronic noncancer
pain. 0000000000001293

50. Nugent SM, Morasco BJ, O'Neil ME, et al. The effects of cannabis among adults with chronic pain and an overview of general harms. Ann Intern Med 2017;167(5):319-331. https://doi.org/10.7326/ $\mathrm{m} 17-0155$

51. Alsherbiny MA, Li CG. Medicinal cannabis - potential drug interactions. Medicines 2019;6(1):3. https://doi.org/10.3390/medicines6010003

52. Moodley K. A place for ethics, law and human rights in healthcare. In: Moodley K, ed. Medical Ethics, Law, and Human Rights: A South African Perspective. 2nd ed. Pretoria: Van Schaik Publishers, 2017:3-6.

53. Hayry M. Prescribing cannabis: Freedom, autonomy, and values. J Med Ethics 2004;30(4):333-336. https://doi.org/10.1136/ime.2002.001347
54. Cohen $\mathrm{K}$, Weinstein A. The effects of cannabinoids on executive functions: Evidence from cannabis and synthetic cannabinoids - a systematic review. Brain Sci 2018;8(3):40. https://doi.org/10.3390/ brainsci8030040

55. Englund A, Morrison PD, Nottage J, et al. Cannabidiol inhibits THC-elicited paranoid symptoms anglund A, Morrison PD, Nottage J, et al. Cannabidiol inhibits THC-elicited paranoid symptoms
and hippocampal-dependent memory impairment. J Psychopharmacol 2013;27(1):19-27. https://doi and hippocampal-dependent $\mathrm{m}$

56. Shah D, Chand P, Bandawar M, Benegal V, Murthy P. Cannabis induced psychosis and subsequen psychiatric disorders. Asian J Psychiatr 2017;30:180-184. https://doi.org/10.1016/j.ajp. 2017.10.003

57. Du Toit BM. Cannabis in Africa: A survey of its distribution in Africa, and a study of cannabis use and users in multi-ethnic South Africa. Rotterdam: A A Balkema, 1980.

58. Chanock M. The Making of South African Legal Culture 1902 - 1936: Fear, Favour and Prejudice. Cambridge: Cambridge University Press, 2001:20-36.

59. De Vos P. Con Court cannabis judgment: What was the reasoning and what does it mean? Constitutionally Speaking, September 2018. https://constitutionallyspeaking co.za/con-courtcannabis-judgment-what-was-the-reasoning-and-what-does-it-mean/ (accessed 21 August 2019).

60. Duvall CS. Drug laws, bioprospecting and the agricultural heritage of cannabis in Africa. Space Polity 2016;20(1):10-25. https://doi.org/10.1080/13562576.2016.1138674

61. Stein D. Position statement on cannabis. S Afr Med J 2016;106(6):569. https://doi.org/10.7196/ samj.2016.v106i6.10863

62. World Health Organization. The Health and Social Effects of Nonmedical Cannabis Use. Geneva WHO, 2016.

Accepted 10 October 2019. 